\title{
El humanismo en la formación del médico. Papel de la neurociencia y la sicología cognitiva
}

\author{
Humanism in the training of the doctor. \\ Role of neuroscience and cognitive psychology
}

JOSÉ RICARDO NAVARRO-VARGAS', GUSTAVO REYES-DUQUE G. ${ }^{2}$

\begin{abstract}
The objective of this article is to present a proposal for professional training consistent with the vocation of the doctor. From the cognitive psychology and the neuroscience the praxis of the humanism is approached, without trying to deepen but to give motivating ideas that allow to transform the medical education with educational innovations. The article includes 3 components, a clinical case, a new view from neuroscience and cognitive psychology, and a proposal that welcomes these innovations directly related to humanism, to transform education in the classrooms and in the various practices of medicine and Health Sciences.
\end{abstract}

\section{RESUMEN}

El objetivo del presente artículo es exponer una propuesta para la formación profesional consecuente con la vocación del médico. Desde la psicología cognitiva y la neurociencia se aborda la praxis del humanismo, sin pretender profundizar sino dar unas ideas motivadoras que permitan transformar la educación médica con innovaciones educativas. El artículo comprende 3 componentes, un caso clínico, una nueva mirada desde la neurociencia y la sicología cognitiva, y una propuesta que acoja estas innovaciones directamente relacionadas con el humanismo, para transformar la educación en las aulas y en las diversas prácticas de medicina y las ciencias de la salud.
Key words: Humanism, medicine, altruism, professional practice, cognitive neuroscience, psychology.

\section{Palabras clave:}

Humanismo, medicina, altruismo, práctica profesional, neurociencia cognitiva, sicología.

Profesor titular de medicina Universidad Nacional de Colombia, Expresidente S.C.A.R.E. Secretario científico de la CLASA.

2 Director ejecutivo S.C.A.R.E. Asesor en educación médica del Ministerio de Salud y Protección Social y del Ministerio de Educación.

Fecha de recepción: 23 de abril de 2018

Fecha de aceptación: 23 de abril de 2018

\section{ORCID}

https://orcid.org/0000-0003-2548-1325

Correspondencia:

José Ricardo Navarro-Vargas

Email: jrnavarrov@unal.edu.co 


\section{Introducción}

Evin n este artículo se revisarán 3 componentes, en primer lugar un caso clínico (mi caso) que sirve de introducción al fenómeno cotidiano de la consulta médica y el manejo profesional o no que se le da a los pacientes. Enseguida se revisará la contribución que aporta la neurociencia y la sicología cognitiva en la comprensión de estos fenómenos y su abordaje, y finalmente una propuesta que surge de estos conocimientos.

Mi Caso clínico: una paciente nos consultó hace un par de meses por una afección en el cuello y en la espalda que en cuestión de 1 mes, pese a tomar distintos analgésicos (acetaminofen, AINE, tramadol, hidrocodona) no solo, no había logrado aliviar el dolor sino que había empeorado hasta el punto de impedirle laborar e interferir con el sueño. Consideramos que debía verla un neurocirujano y le recomendamos un profesor de neurocirugía de alto reconocimiento en Bogotá-Colombia. El neurocirujano la vio en consulta particular y en un corto tiempo (menos de 10 minutos) decidió que requería una resonancia magnética cervical y dorsal. Cinco días después cuando la paciente ya tenía el reporte del estudio fue a control y el neurocirujano revisó la resonancia y consideró que estaba completamente normal. Le dijo a la paciente que probablemente su problema era de estrés y que debía consultar con un siquiatra.

La paciente desconsolada nuevamente nos buscó y nos dijo que ahora ya no sabía qué hacer, que el dolor la estaba volviendo loca. Le recomendamos otro colega neurocirujano, que trabajaba en otra ciudad, en Cali (Valle), y que se destacaba por brindar un trato muy humano a los pacientes. Cuenta la paciente que este otro neurocirujano la escuchó con mucha atención, ella, bacterióloga de profesión le contó que era hipotiroidea y que había suspendido el tratamiento con Levotiroxina por cerca de 2 meses; alguien le recomendó "descansar" del medicamento por 1 mes, y ella había viajado al exterior por 3 semanas y durante este tiempo, casi 2 meses, no había vuelto a tomarlo. A su regreso a Bogotá, comenzó a presentar una gran debilidad, adinamia, astenia y edema en cara. Consultó a un médico que le recomendó reiniciar la suplencia tiroidea con urgencia y había mejorado de sus síntomas constitucionales pero le había aparecido este dolor en la espalda y en el cuello, que "no mejoraba con nada". El médico la examinó y le explicó que posiblemente el cuadro de hipotiroidismo había afectado los forámenes por donde emergen los nervios espinales (algo así como si el coloide de la tiroglobulina hubiera ocluido los forámenes). Le recomendó una tracción cervical por 10 minutos, 2 veces/día. La paciente le preguntó dónde adquiría el aparato pues ella no conocía la ciudad; él le dijo que lo esperara, que atendía 2 pacientes más, luego de lo cual la llevaría al almacén y le enseñaría a armar el aparato. Figura 1.

Así fue y luego de 5 días de tratamiento la paciente se mejoró completamente. Le desapareció el dolor como por arte de magia. Surge la pregunta con

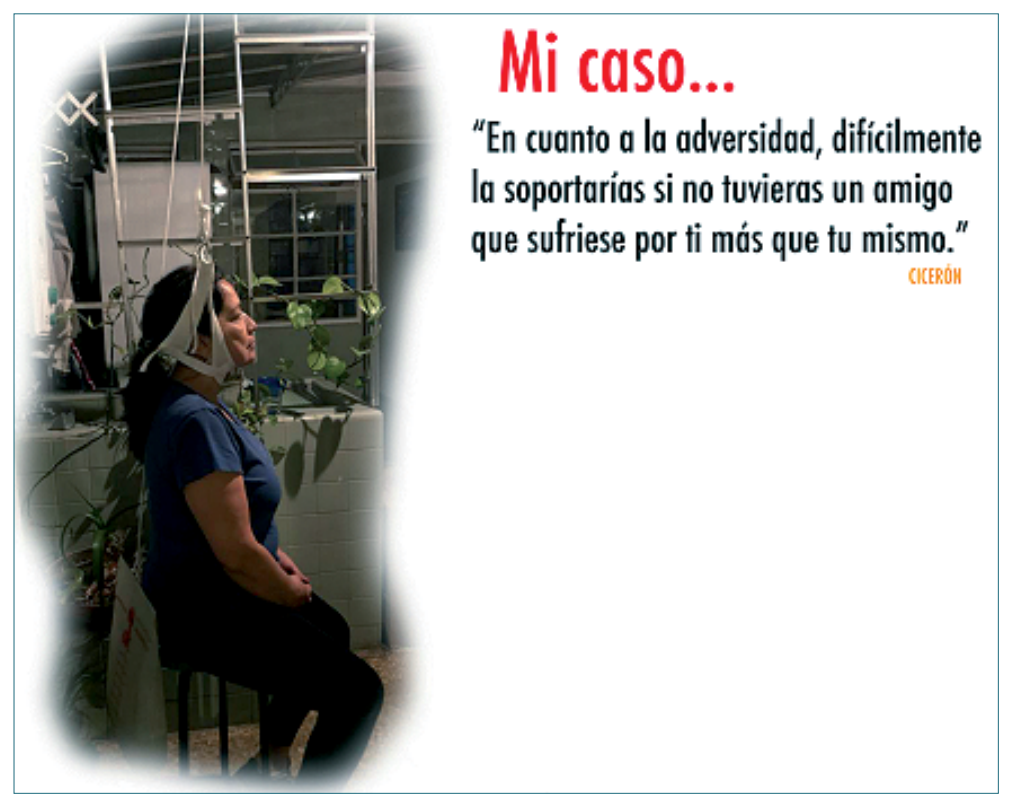

Figura 1. La paciente con el sistema de tracción cervical. 
respecto a la mejoría dramática: ¿sería por la tracción cervical o por la empatía, el altruismo y profesionalismo con que la trató el especialista?

Una nueva mirada desde la Neurociencia y la Sicología cognitiva: para abordar la nueva mirada exploraremos los aportes formativos desde la neurociencia (más específicamente neuroeducación) y la psicología cognitiva. Figura 2.

Para comprender el concepto de inteligencia ejecutiva explicaremos algunos conceptos muy básicos del desarrollo del cerebro.

El cerebro opera sobre códigos heredados (genes) que expresan cambios o momentos de maduración a diferentes edades. Hay progresividad. En la Figura 3 se puede apreciar como el cerebro va en una banda en marcha que es el tiempo (tiempo 1, tiempo 2, tiempo n). En ciertos tiempos el código genético presiona que se desarrolle un área específica. Además, de su código, tiene plasticidad para modificar su estructura y desarrollo; es decir, al llegar a determinado tiempo, se abre como una ventana y ese código permite que interactúe con el medio externo y se formen nuevas sinapsis. Esta situación es facilitada por la plasticidad cerebral.

La Figura 4 muestra el cerebro con unas ventanas cerradas y una abierta la cual, mediante la plasticidad facilita el desarrollo expresado por el aumento de sinapsis. En síntesis, el cerebro opera sobre códigos heredados, pero con plasticidad, mayor al nacer y menor en los viejos. Necesita las ventanas para interactuar con el medio ambiente. Por otra parte, el cerebro en construcción no es un proceso continuo, homogéneo y sincrónico consigo mismo y con el tiempo. Es decir, el desarrollo es asincrónico y tiene tiempos diferentes. Son ventanas que se abren en un tiempo determinado y permiten que entre esa información del entorno para lograr mayor desarrollo y sinapsis. Luego se cierran y abren otras. Los tiempos cuando se abren esas ventanas son críticos. Se necesita la expresión del código, la plasticidad en acción y un entorno enriquecido para alcanzar el máximo desarrollo (por eso en los programas académicos los docentes deben realizar ajardinamiento; es decir, preparar el terreno como el jardinero para que la mezcla entre código genético, plasticidad y entorno enriquecido de estímulos y emociones logren el máximo desarrollo de esa parte del cerebro).

Hay una zona del cerebro que se comporta como las ventanas mencionadas y está relacionada con el desarrollo de habilidades que nos hacen muy hu-
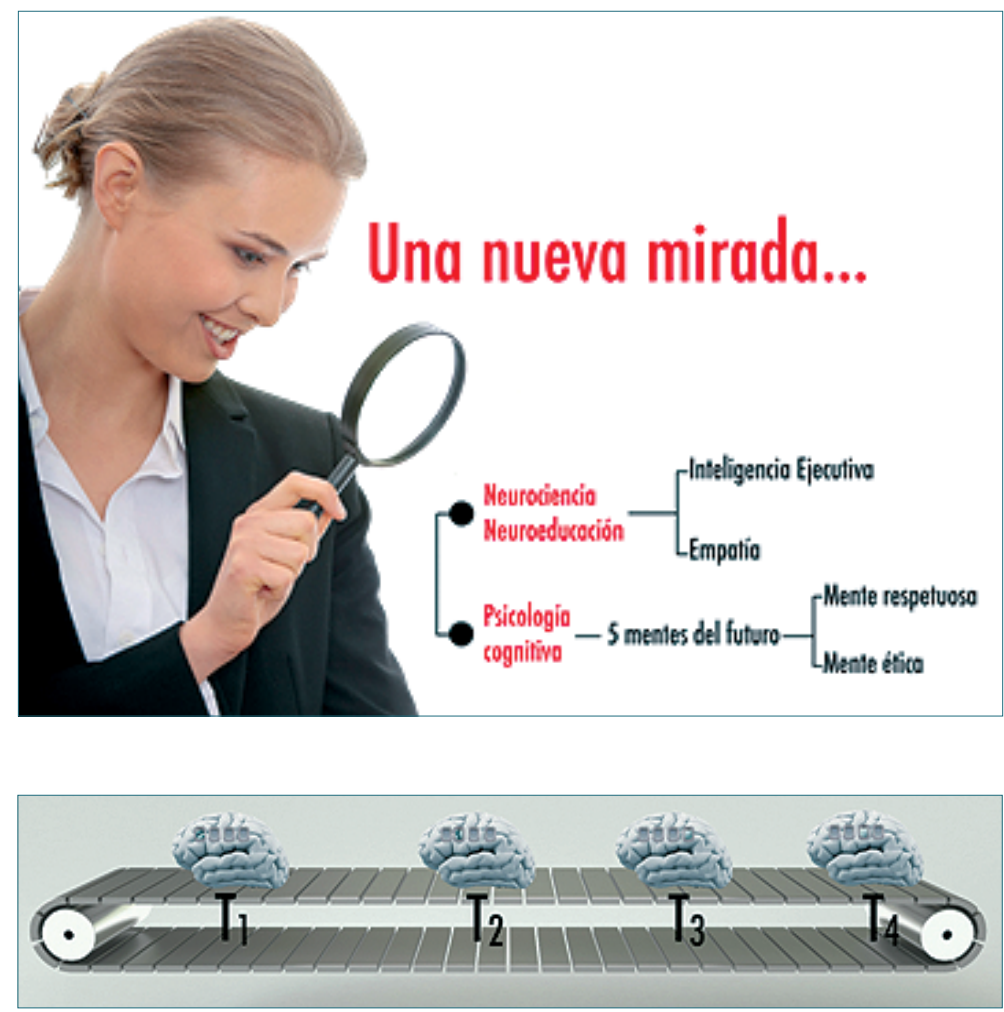

Figura 2. Una nueva mirada: neurociencia y sicología cognitiva.

Figura 3. Desarrollo del cerebro a través del tiempo. 


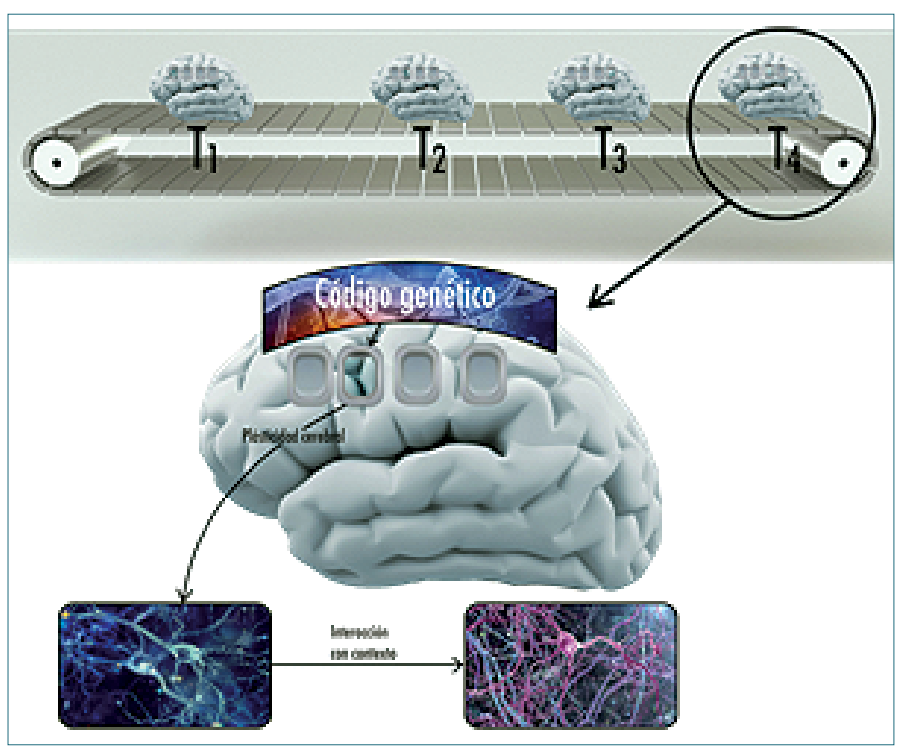

Figura 4. El cerebro y las ventanas de apertura a su desarrollo y crecimiento.

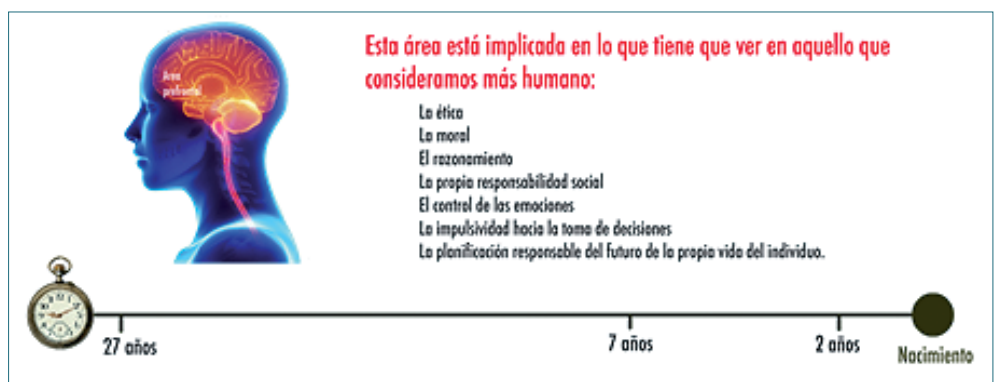

Figura 5. Desarrollo asincrónico del cerebro. manos. Se trata del área prefrontal del cerebro, que se encarga de la ética, la moral, el razonamiento, el control de las emociones, etcétera. Pues esta zona se comporta como una ventana que se abre entre los dos años de manera muy activa hasta los siete años y luego se enlentece hasta los 27 años. Figura 5. Es decir, hasta los 27 años estamos madurando; los estudiantes de pregrado y posgrado de salud tienen un desarrollo incompleto, no son personas con proyectos de vida acabados, son muy susceptibles a la formación en estas áreas. En esta época se activa la ventana, y mediante la plasticidad y el entorno favorable se aumentan las sinapsis.

Lo más interesante de saber es que el área prefrontal sufre un retraso en la maduración considerable.

Un retraso en la maduración que es biológico, y esta área está implicada en lo que tiene que ver con lo que consideramos más humano, como la ética, la moral, el razonamiento, la propia responsabilidad social, el control de las emociones, la impulsividad hacia la toma de decisiones y la planificación responsable del futuro de la propia vida del individuo. Solo termina de madurar hasta los 25-27 años. Esto quiere decir que deberíamos prolongar la adolescencia y tener estas consideramos para la formación de profesionales: Son susceptibles de humanizarlos en gran extensión.

Estas propiedades o funciones identificadas precisamente en el área prefrontal es lo que algunos autores como José Antonio Marina denominan la inteligencia ejecutiva[1]. Figura 6.

\section{Inteligencia ejecutiva}

Tal vez muchos de los errores educativos que hemos padecido proceden de haber intentado educar de manera exclusiva, la inteligencia cognitiva, proporcionando conocimientos a los niños, y la inteligencia emocional, intentando fomentar sus sentimientos 


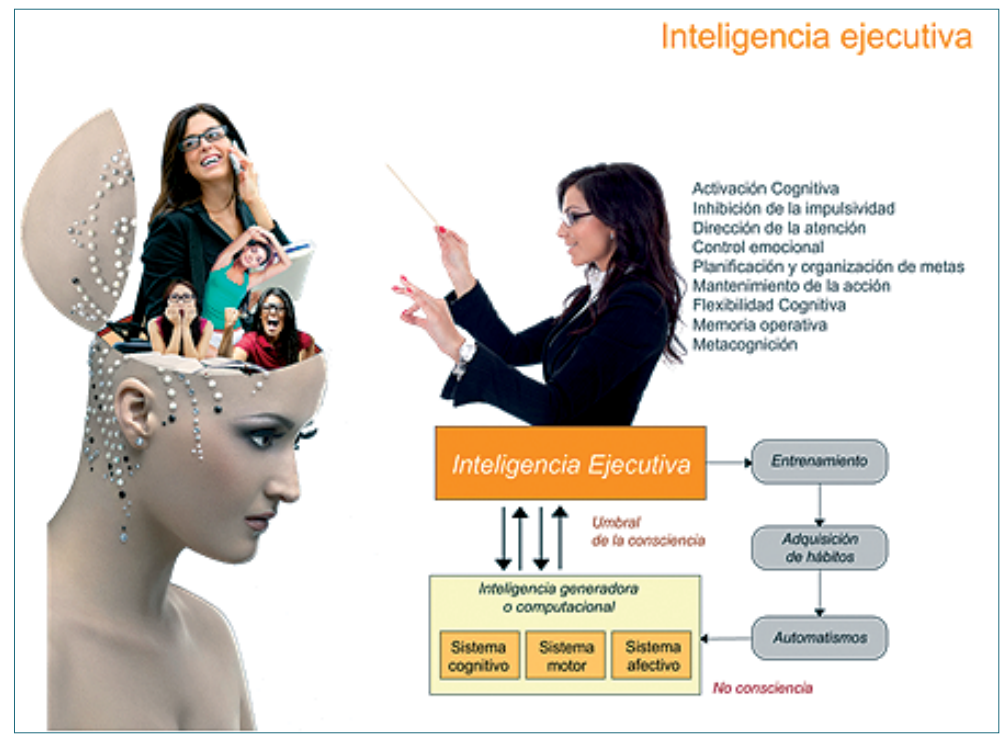

Figura 6. Inteligencia ejecutiva.

agradables, descuidando la educación de la inteligencia ejecutiva. Desde múltiples campos de investigación emerge la idea de una inteligencia ejecutiva, que organiza a todas las demás y tiene como gran objetivo dirigir la acción (mental o física), aprovechando nuestros conocimientos y nuestras emociones. Marina propone una teoría de la inteligencia que comience en la neurología y termine en la ética. El hilo que conduce de una a otra es la acción.

No vivimos para conocer, sino que conocemos para vivir de la mejor manera posible. El niño no nace con una inteligencia ejecutiva, sino que tiene que adquirirla, de ahí el interés de Marina por tratar el tema en un libro dedicado a padres y docentes.

El autor estudia las funciones ejecutivas básicas, los mecanismos de la inteligencia ejecutiva, y también sus patologías. El fracaso de la inteligencia ejecutiva está presente en los grandes problemas que preocupan a la sociedad, como el consumo de drogas, la pasividad o la agresividad no controlada, de ahí la importancia de educarla.

Se establecen dos niveles de la inteligencia humana, la inteligencia computacional o generadora, nuestra gran productora de ocurrencias, de la que surgen los sentimientos y los deseos, y la inteligencia ejecutiva. Figura 6. La educación puede actuar construyendo una inteligencia computacional fértil, eficiente y dócil a las metas de la inteligencia ejecutiva, y construyendo una inteligencia ejecutiva eficaz y con buenos criterios de evaluación.

En el primer estrato, el computacional, se hallan las ideas, los sentimientos, deseos, imaginaciones e impulsos; en el segundo, el ejecutivo, encontramos aquellos mecanismos que tratan, con mayor o menor éxito, de controlar, dirigir, corregir, iniciar o apagar todas esas operaciones mentales generadas en el primer nivel. Esa es la pequeña (o gran) batalla que tiene lugar en el interior de cada ser humano, y que resulta en gran medida la principal tarea social, como es el control de la acción. En muchas escuelas europeas, para mejorar el desarrollo de este tipo de inteligencia que tiene que ver con la humanización se instruye a los niños en práctica de yoga. Más recientemente, se está promoviendo la práctica del mindfulness en las escuelas de medicina, con el fin de mejorar el estrés, autocontrol, y control emocional de profesores y estudiantes. Miremos por ejemplo que cada día se publican más artículos con esta estrategia en pubmed. Figura 7.

Al respecto, Wald y colaboradores plantean una serie de estrategias pedagógicas para vincular la teoría a la práctica en la formación de identidad profesional en educación médica para médicos humanistas y con capacidad de recuperación[2].

Las llamadas recientes para una perspectiva expandida sobre educación médica y capacitación incluyen centrarse en las complejidades de la formación de identidad profesional (PIF). Los educadores médicos tienen el desafío de facilitar el proceso activo y constructivo de integración de PIF dentro de enfoques curriculares estandarizados y personalizados y formales e informales. ¿Cómo podemos apoyar mejor el complejo proceso iterativo de PIF para un profesional de la salud humanista y desafiante? ¿Cómo podemos 


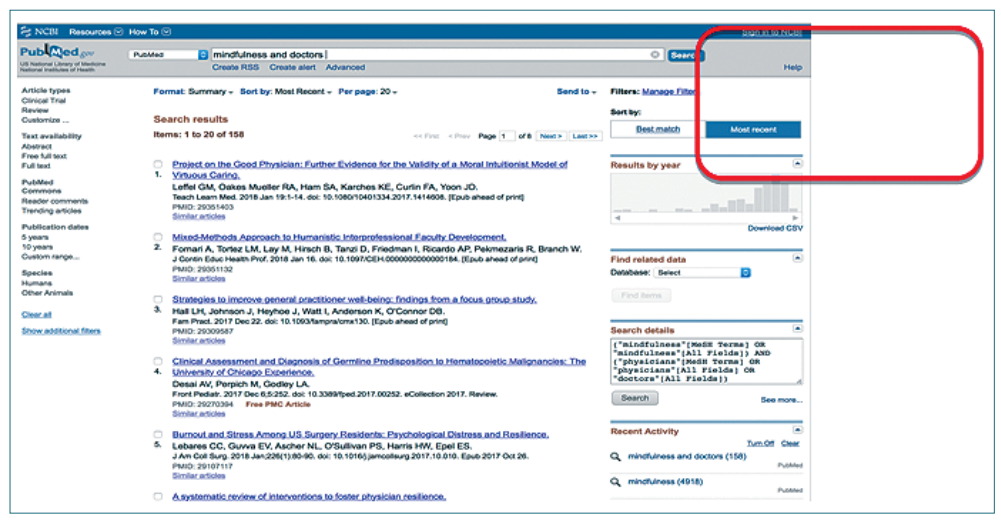

Figura 7. Revisión Pubmed, marzo de 2018. Artículos sobre mindfulness y medicina.

construir con eficacia el aprendizaje reflexivo crítico necesario y las habilidades de práctica para que nuestros alumnos apoyen la formación de una identidad profesional? Los autores presentan tres innovaciones pedagógicas que contribuyen al proceso PIF dentro de la educación médica de pregrado y posgrado (GME) en sus instituciones[2]. Estos son 1) escritura reflexiva interactiva que fomenta la capacidad reflexiva, la conciencia emocional y la resiliencia (a medida que se exploran las complejidades dentro de las interacciones médico-paciente) para el desarrollo personal y profesional; 2) módulos de enseñanza sinérgicos sobre la práctica clínica consciente y respuestas resilientes a las interacciones difíciles, para fomentar la resiliencia del médico y un mayor bienestar para un funcionamiento profesional eficaz; y 3) estrategias para el uso efectivo de un portafolio electrónico de desarrollo profesional y desarrollo de facultades de habilidades de coaching reflexivo en GME. Estas estrategias como "puentes de la teoría a la práctica" incorporan e integran elementos clave para promover y enriquecer el $\mathrm{PIF}$, incluyendo la reflexión guiada, el rol significativo de las relaciones (facultad y compañeros), la atención plena (mindfulness), la retroalimentación adecuada y la creación de entornos de aprendizaje colaborativo. Idealmente, tales innovaciones pedagógicas pueden hacer una contribución significativa para mejorar la calidad de la atención y el cuidado con resiliencia para el ser, relacionarse y hacer de un profesional de la salud un humanista.

\section{Empatía}

La empatía es la participación afectiva de una persona en una realidad ajena a ella, generalmente en los sentimientos de otra persona. Esta viene con el nacimiento, se ha demostrado en diferentes experi-

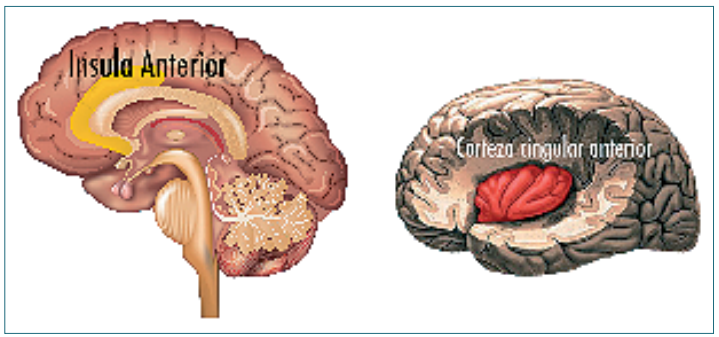

Figura 8. Regiones cerebrales asociadas a la Empatía.

mentos con niños muy pequeños y las neuronas en espejo tienen que ver mucho con este fenómeno humano. También se han identificado áreas del cerebro relacionadas con la empatía. Figura 8.

Para entender más sobre la empatía hay una propuesta de Matthieu Ricard en su libro "En defensa del altruismo: el poder de la bondad"[3] Tras el éxito de El arte de la meditación y En defensa de la felicidad, Ricard con una de las obras más urgentes de nuestro tiempo: un completo tratado del altruismo como solución a la crisis personal y social que asola al individuo occidental. Fue asesor personal del Dalai Lama y uno de los pensadores más influyentes de nuestro tiempo, no tiene dudas: el ser humano posee un enorme potencial de bondad y felicidad. Solo cultivando esta empatía innata seremos capaces de superar un modelo basado en el narcisismo que nos ha abocado al fracaso personal y global. La cristalización del ego, la violencia, la deshumanización o el egoísmo institucional frente a la meditación, la educación, el compromiso o la economía altruista son algunos de los temas que, con el rigor de un científico y la cercanía de un maestro, aborda el autor en su libro más importante hasta el momento. Una obra optimista y generosa, indispensable para superar el desaliento que se impone hoy en nuestra sociedad. 
El autor nos invita a realizar una conciliación entre los imperativos del mundo actual y los intereses no solo para el presente sino para el futuro.

Esta situación se logra mediante el altruismo el cual, según Ricard, aborda desde la argumentación filosófica (desde la cultura oriental) y de las ciencias occidentales (neurociencia). Los imperativos del nuevo siglo son la búsqueda de la felicidad, el cuidado del medio ambiente y una economía para beneficio de todos los seres que habitan el planeta tierra. Éstos deben confrontarse en los intereses; que pueden ser individuales, por el prójimo o por todos los seres del planeta. Estas dos dimensiones deben pensarse no solo para el presente, sino a mediano y largo plazo (dimensión temporal). Lo ideal es que los tres imperativos descritos se enfoquen a los intereses de todos los seres que habitan el planeta hasta una temporalidad que aborde el largo plazo. Esto solo se logra si se promueve el altruismo en el mundo.

En cierta forma el camino para la conciliación de los imperativos en el siglo XXI se debe lograr a través del altruismo. Una definición de altruismo es "la empatía llevada a la acción" como el caso que ocurrió con la paciente y el segundo neurocirujano.

Para entender mejor este concepto se muestra a través de un mentefacto, Figura 10.

De acuerdo al mentefacto, el altruismo es una motivación mediada por buenas intenciones, la cual busca el bienestar de los seres del planeta tierra; se visualiza mediante una acción que se realiza en un momento, pero que tiene disposición permanente y duradera de quién la hace; a su vez le exige que asuma un riesgo y un costo; no obstante, sin sacrificio; en contraste puede generar mucha felicidad. Estas acciones pueden ser aportadas a seres vivos humanos (persona, prójimo o todos los seres) y no humanos. El altruismo tiene dos componentes para que se pueda llevar a la acción: primero, debe darse y reconocerse el valor del otro y segundo la persona que ejecuta la acción debe sentirse afectado por la situación del otro (empatía). Finalmente, el altruismo debe diferenciarse del egoísmo y el egocentrismo. El primero hace referencia a los actos con una intencionalidad que solo busca el beneficio individual; es decir, considera todos los imperativos (descritos en la introducción) solo con un interés: el bienestar individual. Lo segundo tiene que ver con el estado donde los hombres se consideran el centro del planeta sin incluir los hermanos del planeta (los animales y las plantas).

Hay una frase del Dalai Lama que vale recordar: "Se necesita construir un puente entre la vida contemplativa y la vida activa". No solo es reflexionar, no solo es meditar. Hay que actuar. Pero esa actuación debe ser mediada por el altruismo[3].

Otra frase relevante es: "la motivación colorea las acciones". La motivación es un cubo de cristal que debe vislumbrar el color de la tela sobre la cual está puesto. Dice el autor, que se debe visualizar el color o las intenciones que desencadenan la motivación, porque conocer las intenciones (positivas o negativas) permiten diferenciar el altruismo del egoísmo[3].

Burks y Kobus revisan el altruismo en la asistencia sanitaria[4]. Examinan los conceptos de altruismo y empatía entre los estudiantes de medicina y los profesionales en conjunto con las iniciativas de atención médica diseñadas para apoyar el mantenimiento de estas cualidades.

Los ideales altruistas y las cualidades de la empatía

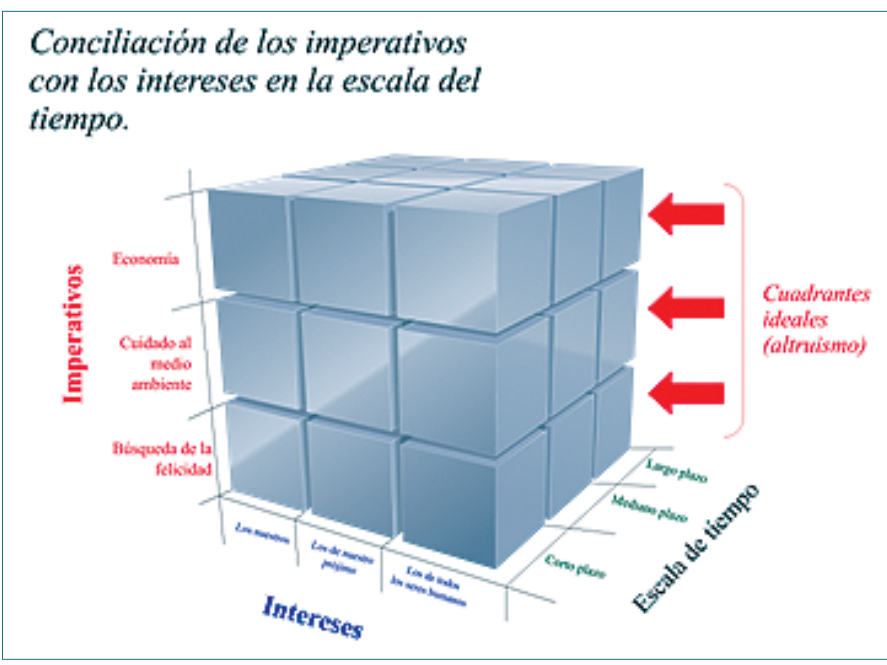

Figura 9. Matriz sobre la conciliación de los imperativos con los intereses en la escala del tiempo. 


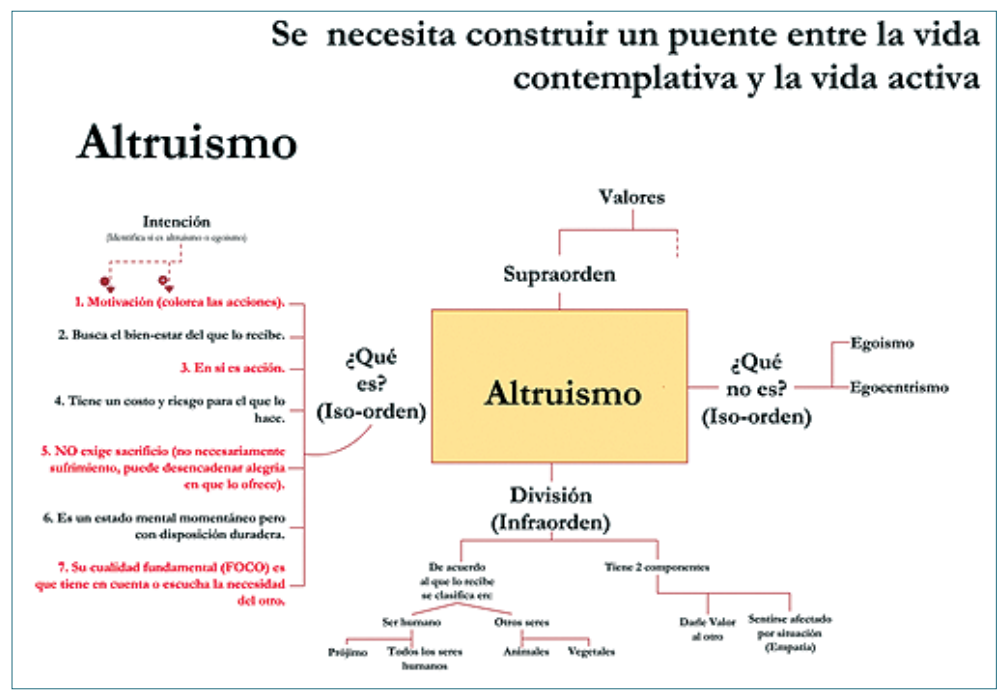

Figura 10. Mentefacto del Altruismo.

parecen disminuir entre algunos estudiantes de medicina a medida que avanzan en su educación. Durante este proceso, los estudiantes se enfrentan a cargas de trabajo cada vez más pesadas, lidian con demandas extenuantes y se familiarizan con las prácticas informales no humanísticas inherentes a la cultura de la medicina. En combinación, estos factores aumentan la probabilidad de que se produzca supresión emocional, desapego de los pacientes, agotamiento y otras consecuencias negativas, quizás como medio de autoconservación. Alternativamente, al tomar una decisión atenta e intencional para esforzarse por el cuidado personal y un equilibrio saludable entre el trabajo y la vida, los estudiantes de medicina pueden mantener actitudes y comportamientos humanísticos y prosociales[4].

La conclusión de estos autores[4] es que promover el altruismo en el contexto de una carrera de salud compensada es contradictorio y equivocado. En cambio, se recomienda un enfoque de atención clínica que sea prosocial y empático. La capacitación en mindfulness, autorreflexión y habilidades emocionales puede ayudar a los estudiantes de medicina y profesionales a reconocer, regular y demostrar la empatía dentro de los encuentros clínicos y profesionales. Sin embargo, las iniciativas de cuidado de la salud para aumentar la empatía y otras cualidades humanísticas serán limitadas a menos que los estudiantes de medicina ofrezcan y acepten una capacitación en habilidades emocionales más práctica y factible. Aparece el mindfulness como una alternativa para mantener al altruismo que es la esencia de las profesiones de la salud.

\section{Psicología cognitiva}

En 2007, Howard Gardner publicó un interesantísimo trabajo titulado "Las cinco mentes del futuro"[5], en el que expone cinco modos generales de uso de la mente, que se enseñan y se fomentan en la escuela, las profesiones liberales y los distintos lugares de trabajo, y que implican, cada una, la utilización de todos los tipos de inteligencia que poseemos. Gardner asegura que, "para enfrentarnos a los retos que este nuevo mundo nos depara, deberíamos empezar a cultivar estas capacidades desde ahora mismo". En la línea de su trayectoria de investigación y pensamiento, el autor nos proporciona, en esta nueva edición revisada y ampliada, cinco mentes que trascienden su famosa teoría de las inteligencias múltiples. Los cinco tipos de funcionamiento mental aparecen como elementos indispensables para prosperar en el mundo actual. Se nos presenta un nuevo orden mundial en el que destacan la hegemonía de la ciencia y la tecnología, la gran cantidad y complejidad de la información, el papel a ser desempeñado por la inteligencia artificial y la gran variedad de contactos entre grupos poblacionales diversos. Configurado así el escenario donde ha de desarrollarse la vida del ser humano, se proponen cinco tipos de mente idóneos para hacer frente a estos nuevos retos.

A diferencia de las ocho inteligencias humanas anteriormente postuladas por el autor, en esta obra se habla de los usos generales de la mente que deben ser fomentados en la escuela, en la sociedad y en el ámbito laboral. Las mentes que idealmente deben ser cultivadas en el futuro son la mente disciplinada, la 
sintética, la creativa, la respetuosa y la ética. Se trata de poner en funcionamiento todo el potencial del ser humano en una suerte de mentes auto-contenidas.

La mente disciplinada es aquella que sabe utilizar el modo de pensar de las principales áreas de conocimiento humano (matemáticas, historia, arte, etc.). En este punto, el autor se enlaza con uno de los tópicos de investigación más importantes en el campo de la psicología educativa: el de los procesos de autorregulación del aprendizaje.

La mente sintética destaca por su capacidad para manejar, seleccionar y establecer conexiones entre cantidades ingentes de información. Es una capacidad innata escasamente cultivada a lo largo del desarrollo, por lo que puede terminar atrofiándose si no se ejercita, o pervirtiéndose cuando se hace de modo inapropiado.

La mente creativa supone "ir más allá del conocimiento y la síntesis existentes para plantear nuevas preguntas, proponer nuevas soluciones, dar forma a obras ampliando los géneros existentes o configurar otros nuevos; la creatividad incorpora una o más disciplinas establecidas y requiere un campo informado en el que se pueda emitir juicios acerca de la calidad y la aceptabilidad de la creatividad".

Los anteriores tipos de funcionamiento mental precisan de un conjunto de aspectos éticos y morales para funcionar realmente al servicio del progreso y el desarrollo humano. Es aquí donde entra en juego el papel de las mentes respetuosa y ética.

La mente respetuosa acepta las diferencias existentes entre los seres humanos, aprende a vivir con ellas y valora a quienes forman parte de esos grupos. Se nos advierte del peligro del respeto superficial, del interesado y del derivado de lo políticamente correcto. El respeto debe impregnar todas las áreas en las que se desenvuelve nuestra vida y que, de un modo u otro, tienen que ver con otros sujetos. En un mundo cada vez más interconectado, no se entienden, y se entenderán aún menos, las manifestaciones de ignorancia, de intolerancia o falta de respeto hacia otros. Así que la mente respetuosa trata de observar y aceptar las diferencias entre los grupos humanos, e intenta comprender a los otros (sin caer en estereotipos ni caricaturas) y trabajar con ellos para un fin común. Es indispensable para vivir en un mundo de más de seis mil millones de habitantes, debe ir más allá de la tolerancia de las diferencias, mostrar empatía, interés y afecto. Es necesario enseñar con materiales neutrales y por medio de relaciones cooperativas y solidarias, establecer preceptos que refuercen la identidad de grupo, predicar con el ejemplo. Desde niños aprendemos acerca de los conceptos de inclusión y exclusión, amor y odio, respeto y tolerancia, dependiendo del comportamiento observado y aprendido de los adultos.

La mente ética es consciente de su papel en cada momento, de los requisitos que debe cumplir, de los límites y los estándares de la conducta correcta. Debe trascender la propia individualidad y pensarse como elemento de las diversas comunidades de las que forma parte. La mente ética empieza en el hogar, desde la observación de los padres y el gusto o disgusto por el trabajo, sus comentarios y su seriedad hacia él, si representa un gusto intrínseco o sólo el sustento económico. Los niños imitarán las conductas de sus padres y éstas se interiorizarán en ellos, pues los adultos serán modelos del comportamiento futuro de sus hijos, de éstos dependerá tener una base ética sólida, la responsabilidad ante la profesión y ante la sociedad en general.

Para Gardner estas cinco mentalidades serán cada vez más valoradas de acuerdo con el contexto actual de globalización y la supremacía de las Tecnologías de Información y Comunicación (TICs) y el lugar que ocupen dependerá de los objetivos y valores de cada sociedad, los sistemas educativos posibilitarán el cultivo de este potencial humano, y la calidad de vida dependerá de ello.

Con las mentes del futuro, aunque no es deseo expreso del autor, se centra desmesuradamente en el funcionamiento mental de los líderes del futuro, sobre todo en el área más cognitiva (disciplina, síntesis y creatividad); el reparto del cultivo de las mentes respetuosa y ética es, sin embargo, más igualitario.

\section{Una Propuesta}

Es importante extraer los conocimientos de la neurociencia y de la sicología cognitiva que están íntimamente relacionados con el humanismo para llevarlos a las aulas y a las prácticas con el fin de que seamos mejores personas, mejores seres humanos, mejores profesionales.

\section{Conclusión}

El propósito del artículo es disponer de una estrategia educativa a partir de la neurociencia y de la sicología cognitiva para la transferencia de conocimiento desde el docente y la apropiación del mismo por el estudiante, con un lenguaje sencillo, que permita seleccionar un material formativo sin excederse en expectativas de aplicación ni en falsos conceptos (neuro- 
mitos); de esta forma se pretende pasar del empirismo a una formación del humanismo basado en la mejor evidencia. Algunos ejemplos de neuromitos: "clasificar a los estudiantes por tipos de aprendizaje de cerebro derecho e izquierdo" (todos aprendemos con ambos hemisferios); lo que debemos hacer es dar un tema en múltiples formatos. La enseñanza debe ser global. "El niño al nacer hace más sinapsis", entonces hay que entregarle más educación y no dejarlo jugar, por ejemplo. "Sólo utilizamos el 10\% del cerebro". Falso, en el pensar lo utilizamos todo. "El efecto Mozart es mentira". "Loro viejo no aprende hablar". "El conocimiento con sangre entra". "Mientras más leo de humanismo soy más humano". Cuidado con el "asignaturismo". "El hombre y la mujer aprenden diferente". "El cerebro funciona como un computador".

\section{Referencias}

1. Marina José Antonio. La inteligencia ejecutiva e-book. Editorial Ariel, 2012. https:// www.casadellibro.com/ ebook-la-inteligencia-ejecutivabook/9788434401686/1986902

2. Wald HS, Anthony $D$, Hutchinson TA, Liben S, Smilovitch M, Donato AA. Professional identity formation in medical education for humanistic, resilient physicians: pedagogic strategies for bridging theory to practice. Acad Med. 2015; 90 (6): 753-60.

3. Matthieu R. En defensa del altruismo. El poder de la bondad. Editorial Urano, 2016. http:// www.edicionesurano.es/es-es/ catalogo/catalogos/ficha-tecnica. html?id=001000343

4. Burks DJ, Kobus AM. The legacy of altruism in health care: the promotion of empathy, prosociality and humanism. Med Educ. 2012; 46(3): 317-25.

5. Gardner H. Las cinco mentes del futuro. Un ensayo educativo.

Editorial Paidós. Barcelona, España, 2005. ISBN: 84-493-1675-8. 